\title{
Helicobacter pylori infection: association with hashimoto's thyroiditis
}

\begin{abstract}
Autoimmune thyroid diseases (ATDS) are multifactorial conditions that result from genetic predisposition in combination with environmental risk factors. Helicobacter Pylori (HP) infection as an environmental risk factor has been proposed to initiate the antigenic components of the thyroid cell membrane and may play a leading role in the onset of the auto immune diseases such as Hashimoto's thyroiditis (HT).
\end{abstract}

The Aim: To investigate the association between H.P infection and HT and the prevalence of cag. A positive strains H.P in the patients.

Methods: The study include 40 female patients with Hashimoto's thyroiditis as a case group and 30 healthy female as control group. HP antigen in stool samples using unamplified enzyme immunoassay and Cag. Ainserum samples using an enzyme linked immunoassay method (ELISA). Anti-thyroid peroxidase antibodies (anti TPO) and thyroid function tests thyroid stimulating hormone (TSH) and thyroxine (T4) were determined.

Results: There is statistically significant association between H P and HT (Odd ratio $=8.1$, $95 \%$ confidence interval: $3-30.1, \mathrm{p}<0.001)$. Also statistically significant association between presence of Cag-A positive strains of HP and HT (odd ratio=5.3, $\mathrm{p}=0.001$ ). To establish the significant correlation between HP and HT further and more specialized studies are needed.

Conclusion: There was a significant association between Hashimoto's thyroiditis and H.P infection and significant prevalence of cag. A positive strain of H.P positive patients and HT.

Keywords: Helicobacter pylori, hashimoto's thyroiditis, gastritis
Volume 4 Issue 5 - 2016

\author{
Mohamed Korani,' Elsayed Elshayeb, I Ahmed \\ Sonbal ${ }^{2}$ \\ 'Internal medicine, Menuofia University, Egypt \\ ${ }^{2}$ Clinical Pathology Department, Menuofia University, Egypt
}

Correspondence: Mohamed Korani, Internal medicine, Menuofia University, Egypt, Email alaamraouf@hotmail.com

Received: March 09, 2016| Published: April 23, 2016
Abbreviations: ATDS, autoimmune thyroid diseases; HP, helicobacter pylori; TSH, thyroid stimulating hormone; ELISA, enzyme linked immunoassay Method; HT, hashimoto's thyroiditis

\section{Introduction}

Auto immune thyroid diseases (ATDS) are represented, essentially, by Hashimoto's thyroiditis (HT), grave's disease and atrophic thyroiditis. ${ }^{1}$. Atypical marker of HT is the presence of autoantibodies against thyroglobulin and thyroid peroxidase (TPO Abs). ${ }^{2}$ Both genetic and environmental factors are involved in the pathogenesis of ATDS. ${ }^{3}$ Some bacteria and viruses are suspected of being able to mimic the antigenic profile on the thyroid membrane and play an important role in the onset of auto immune diseases. ${ }^{4,5}$ Helicobacter pylori (HP) infection as an environmental risk factor is a gram-negative, mobile bacterium, which typically colonizes and infect the gastric mucosa; the most virulent strains can be identified by the presence of the cytotoxin- associated gene A (cag- A) antigen. ${ }^{6}$ Antibodies are produced in reaction to HP antigens in the human body, including thyroid tissue.?

It has also been suggested that cag A positive strains of the H.P increase the risk for ATD, especially in women and they involved in the pathogenesis of HT this is based on the detection of monoclonal antibodies against cag A of H.P strains which cross react with follicular cells of thyroid gland and also on the fact that H.P strains possessing the cag A pathogenicity island carry a gene encoding for an endogenous peroxidase. ${ }^{6}$ Eradication of H.P infection is followed by a gradual decrease in the level of thyroid auto antibodies, ${ }^{8}$ suggest that H.P antigens involved in the development of auto immune thyroiditis or that auto immune function in this disease may increase the likelihood of H.P infection. ${ }^{9}$ Also there is significant decrease of free T3 and free T4 in H.P infection. ${ }^{10}$ Lymphoid follicles in the gastric mucosa are common in ATD, and H.P infection plays a causative role. ${ }^{11}$ The aim of this study was to investigate the association between helicobacter pylori infection and Hashimoto's thyroiditis and the prevalence of cag A positive strains of H.P among the patients.

\section{Materials and methods}

The study included 40 female patients affected by Hashimoto's thyroiditis. The disease was diagnosed by clinical criteria, increase $\mathrm{TSH}$, low free T4 and positive anti. Thyroid peroxidase anti body and 30 healthy female as the control group. The study inclusion criteria were absence of other diseases, a negative for antimicrobial drugs use for at least three months absence of dyspeptic symptoms (epigastria pain, nausea, heartburn) gastric diseases or previous treatment for Helicobacter pylori eradication. The patients and control groups were selected from the out patients clinic and internal medicine deportment in Menoufia university hospital after written informed consent before participating in the study.

All subjects were subjects to thorough history taking, complete physical examination and laboratory investigations including:

\section{i. Thyroid function tests TSH and free T4.}

Assay principle: Serum TSH and free T4 determined using immulite/ immulite 1000TSH and free T4 is a solid. Phase competitive chemo luminescent enzyme immunoassay. ${ }^{12}$ 
ii. Thyroid auto anti body (Anti- TPO) was done using enzyme linked immune sorbent assay. ${ }^{13}$

iii. Stool analysis for H.P antigen fresh stool samples were obtained and tested using amplified enzyme immune assay for detection of ${ }^{14}$ H.P antigen.

iv. Special IGE antibodies against cytotoxic- associated gene A (cag A) will be done in the sera of all patients with positive H.P positive antigen by ELISA method. ${ }^{15}$ The kit (EUROIMMUN) recommends interpreting results as follow:
a. $<16 \mathrm{Ru} / \mathrm{ml}$ : negative
b. $>16$ to $<22 \mathrm{Ru} / \mathrm{ml}$ : borderline
c. $\geq 22 \mathrm{Ru} / \mathrm{ml}$ : positive
d. $R U=$ relative units.

v. Routine investigations

a. Complete blood picture

b. Renal function tests

- Blood urea and creatinine

- Liver function tests

Table I Clinical and biochemical characteristics of the investigated groups

\begin{tabular}{llll}
\hline \multirow{2}{*}{ Parameter } & \multicolumn{1}{l}{ Case group } & Control group & \multirow{2}{*}{ P value } \\
\cline { 2 - 3 } & no= $\mathbf{4 0}$ & $\mathbf{n o}=\mathbf{3 0}$ & \\
\hline Age & $32.6 \pm 10.9$ & $33.7 \pm 7.8$ & 0.15 \\
Free T4 $(\mathrm{ng} / \mathrm{dl})$ & $0.74 \pm 1.006$ & $1.33 \pm 0.493$ & $0.002^{*}$ \\
$\mathrm{TSH}(\mathrm{IU} / \mathrm{mL})$ & $13.8 \pm 12.6$ & $2.7 \pm 1.08$ & $<0.00 I^{*}$ \\
\hline
\end{tabular}

$\mathrm{T}_{4}:$ Throxine; $\mathrm{TSH}:$ Thyroid stimulating hormone $\mathrm{p} \leq 0.05=$ significant

Table 2 The helicobacter pylori infection and Cag-A positivity among the studied groups

\begin{tabular}{|c|c|c|c|c|c|c|c|c|c|}
\hline \multirow{2}{*}{ Groups } & \multirow{2}{*}{ Number } & \multicolumn{2}{|c|}{ H.P -ve } & \multicolumn{2}{|c|}{ H.P +ve } & \multicolumn{2}{|c|}{ Cag-A +ve } & \multicolumn{2}{|c|}{ Cag-A -ve } \\
\hline & & No. & $\%$ & No. & $\%$ & No. & $\%$ & No & $\%$ \\
\hline Case & 40 & 24 & 60 & 16 & 40 & 12 & 75 & 4 & 25 \\
\hline Control & 30 & 27 & 90 & 3 & 10 & 1 & 33.3 & 2 & 66.7 \\
\hline \multicolumn{2}{|l|}{$P$} & \multicolumn{4}{|c|}{$0.005^{*}$} & \multicolumn{4}{|c|}{$0.001 *$} \\
\hline \multicolumn{2}{|l|}{ OR } & \multicolumn{4}{|l|}{6} & \multicolumn{4}{|l|}{6} \\
\hline \multicolumn{2}{|c|}{ 95\% CL (LL-uL) } & \multicolumn{4}{|c|}{$1.555-23.148$} & \multicolumn{4}{|c|}{$2.422-30.148$} \\
\hline
\end{tabular}

$P: p$ value for chi square test

*Statistically significant at $\mathrm{p} \leq 0.05$

\section{Discussion}

H.P infection is found worldwide and affects up to $50 \%$ of the population of developed countries, and the most virulent strains are identified by the presence of cag. A antigens. ${ }^{17}$ Our results showed significant association between Hashimoto's thyroiditis and H.P infection. In a study conducted by Larizza et al. ${ }^{18}$ H.P was proposed as one of the etiologic causes of thyroid autoimmune disease. Bertolat et al. ${ }^{8}$ showed that individuals with high titre of anti-TPO were significantly affected by H.P infection and reduction of H.P causes significantly reduction in anti-TPOAb. Luis et al. ${ }^{9}$ Showed that the i. Serum aspartate transaminase

ii. Serum a alanine transaminase

\section{Statistical analysis}

Data were fed to the computer and analyzed using IBM SPSS software package version 20.0.0. ${ }^{16}$

\section{Results}

In this study 40 female patients were affected by Hashimoto's thyroiditis as a case group and 30 healthy female as a control group. There was no statistically significant difference between the two studied groups as regard the mean age $(p=0.15)$. The levels of the thyroxine and thyroid stimulating hormone were statistically significantly higher in case group compared with the control group ( $\mathrm{p}=$ $0.002, \mathrm{p}<0.001$. respectively). The results showed that Hashimoto's thyroiditis patients and positive for H.P stool antigen were $16(40 \%)$ and for the control group only 3 individuals were positive for the H.P stool antigen (10\%) indicating a statistically significant association between H.P infection and Hashimoto's thyroiditis $(\mathrm{OR}=6,95 \%$ confidence interval $1.555-23.148, \mathrm{p}<0.005)$. In the case group 12 patients $(75 \%)$ of the H.P infection positive were positive for the Cag. A antigen compared to only one in the control group (33.3) indicating a statistically significant association between the Hashimoto's thyroiditis and Cag. A positive strains of H.P. $(\mathrm{p}=0.001)$ (Tables 1 $\& 2)$. 
dyspeptic patients were first selected based on their positivity and then investigated for auto immune thyroiditis which is substantially different from the method of our study.

In other study conducted on 20 patients and 20 normal people by Franceschi et al..$^{20}$ the prevalence of HP infection in the patients and the control group were the same based on these finding they deduced that a relation between HP infection and H.T was unlikely. It seems that the limited sample size of this study was the cause of the negative outcome. As the fetal origin of the thyroid gland is the same as the stomach and digestive tract, we can consider thyroid cells as a digestive tract cells, capable of accumulating, concentrating and combining iodine compounds. Both thyroid and stomach have the ability to concentrate iodine. In addition, in terms of cell polarity, the presence of apical microvilli, synthesis and excretion of glycol protein (thyroglobulin and mucin) they are alike. Superficial parietal cell antigens of the stomach are homologous with protein portion of thyroid peroxides enzyme. Fetal and structural similarity of these two organs may justify their simultaneous involvement in some diseases and it is realized that HP infection could trigger the mechanism of auto immune reaction such as increased thyroid antibodies. ${ }^{21}$

In our study we found a significant prevalence of cag. A positive strain of H.P positive patients and HT, in agreement with Figura et al. ${ }^{22}$ who reported a significant association of helicobacter pylori strains expressing cag. A and autoimmune thyroid diseases in middle aged women. ${ }^{22}$ Regarding the pathogenetic role of HP in the onset of ATDS, it has been postulated that viral and bacterial infections could play a noteworthy role. Cag. A positive H.P strains show some nucleotide sequence similarity to TPO sequence..$^{23}$ A positive linear regression between H.P Abs titres and microsomal auto antibodies and a significant reduction in these antibodies after the H.P eradication have been demonstrated. ${ }^{8}$ Therefore, cross reactivity of the antibodies produce against thyroid antigen structures during H.P infections could potentially in duce a biological effect, ${ }^{24}$ in a similar way to the that H.P infection which triggers the onset of auto antibodies against the $\mathrm{H}+\mathrm{K}+$ - ATPase in the gastric autoimmunity. ${ }^{25}$

Moreover the increased prevalence of the H.T, on the first diagnosis, and the observation that, usually H.P infection starts during child hood, suggest that the bacterium could be present before the onset of the autoimmune disease. ${ }^{26}$ In conclusion, we found a significant association between HP and Hashimoto's thyroiditis, although the strains involved in HT are, prevalently, carriers of Cag-A antigens. These results suggest the execution of screening of HP in ATDs patients, taking into account either the presence of virulent strains in autoimmune diseases and increased H.P prevalence in HT. therefore further and more detailed researches are needed to confirm the results.

\section{Acknowledgments}

None.

\section{Funding}

None.

\section{Conflict of interest}

The authors declare that there is no conflict of interest.

\section{References}

1. Swain M, Swain T, Mohanty BK. Autoimmune thyroid disorders- an update. Indian JCLIN Biochem.2005;20(51): 9-17.
2. Schott M, Scherbaum WA. Autoimmune thyroid disease. Dtsch Atztebl. 2006;103(45): A3023-A3032.

3. Fountoulakies S, Tast soulis A. On the pathogenesis of autoimmune thyroid disease: a unifying hypothesis. Clin Endocrinal (Oxf). 2004; 60(4):397-409.

4. Sterzl I, Hrda P, Potuznikova B, et al. Autoimmune thyroiditis and helicobacter pylori- is there a connection? Neuro Endocrinal lett. 2006;27(Suppl 1):42-50.

5. Rapoport B, Mclach lan SM. Thyroid autoimmunity. $J$ CL in Invest. 2001;108(9):1253-1259.

6. Valtonen VV, Ruutu P, Varis K, et al. Serological evidence for the role of bacterial infections in the pathogenesis of the thyroid diseases. Acta Med Scand.1986; 219(1):105-111.

7. Oshima T, Ozono R, Yano Y, et al. Association of Helicobacter pylori infection with systemic inflammation and endothelial dysfunction in healthy male subject. J Am Coll Cardiol. 2009;45(8):1219-1222.

8. Bertolat G, Montresor G, Tampieri M, et al. Decrease in thyroid antibodies after eradication of Helicobacter pylori infection. $C L$ in Endocrinal (Oxf). 2004;61(5):650-652.

9. de Luis DA, Varela C, de La Calle H, et al. Helicobacter pylori infection is markedly increased in patients with autoimmune atrophic thyroiditis. JCL in Gastroenterol. 2007;26(4):259-263.

10. Trianta Fillidis JK, Gikas A, Merikas E, et al. Relation between Helicobacter pylori infection, thyroid hormone levels and cardio vascular risk factors on blood donors. Hepato gastroenterology. 2009;50(suppl 2): ccexviii-ccexx

11. Gammarota G, Valle D, Cucol, et al. Gastric mucosa-associated lymphoid tissue in autoimmune thyroid disease. Scand J Gastroenterol. 2008;32(9):869-872.

12. Skelley DS, Brown LP, Besch PK. Radio immune assay. CL in Chem. 1973;19(2):146-186.

13. Ruf J, Toubert ME, Czaroneka B, et al. Relationship between immunological structure and thyroid peroxidase. Endocrinology. 1989;125(3):1211-1218.

14. Klein PD, Malaty HM, Martin RF, et al. Noninvasive detection of Helicobacter pylori infection in clinical practice. Am J Gastroenterol. 1996;91(4):690-694.

15. Kricka LJ. Principles of immune chemical techniques. In: Burits CA, Ashwood ER (Eds.), Tietz fundamentals of clinical chemistry. (5th vol), Wound B Saunders company, Philadelphia, USA. 2001:177-194.

16. Kirk Patrick LA, Feeney BC. A simple guide to IBM SPSS statistics for version 20.0 (student edn), Wadsworth Cen gage learing, Belmont, California, USA. 2013.

17. Atherton JCHH. pylori virulence factors. Br Med Bull. 1998;54(1):105120 .

18. Larizza D, Calcaterra V, Martinetti M, et al. Helicobacter pylori infection and autoimmune thyroid disease in young patients: the disadvantage of carrying the human leukocyte antigen-DRB $1 * 0301$ allele. J Clin Endocrinol Metab. 2006;91(11):176-179.

19. Tomasi PA, Dore MP, Fanciulli G, et al. Is there anything to reported association between Helicobacter pylori infection and auto immune thyroid ? Dig Dis Sci. 2005;50(2):385-388.

20. Franceschi F, Satta MA, penland R, et al. Helicobacter pylori infection in patients with Hashimoto's thyroiditis. Helicobacter. 2004;9(4):369.

21. Venturi S, Venturi M. Iodide, thyroid and stomach carcinogenesis: evolutionary story of a primitive antioxidant? Eur J Endocrinal. 1999;140(4):371-372. 
22. Fiqura N, Dicarano G, Lore F, et al. The infection of Helicobacte pylori strains expressing Cag A is highly prevalent in women with auto immune thyroid disorders. J physiol pharmocal. 1999;50(5):817-826.

23. Tomb JF, White O, Kerlavage AR, et al. The complete genome sequence of the gastric pathogen Helicobacter pylori. Nature. 1997;388(6642):539-547.

24. KO GH, Part HB, Shin MK, et al. Monoclonal antibodies against Helicobacter pylori cross-react with human tissue. Helicobacter. 1997;2(4):210-215.
25. D'Elios MM, Appelmelk BJ, Amedei A, et al. Gastric autoimmunity: the role of helicobacter pylori and molecular mimicry. Trends med. 2004;10(7):316-323.

26. Nabwera HM, Nguyen-Van-Tam JS, Logan RF, et al. Prevalence of helicobacter pylori infection in Kenyan Schoolchildren aged315 years and risk factors for infection. Eur J Gastroenterol Hepatol. 2000;12(5):483-487. 